\title{
Publication bias in animal research presented at the 2008 Society of Critical Care Medicine Conference
}

\author{
Una Conradi ${ }^{1}$ and Ari R. Joffe $2,3,4^{*}$
}

\begin{abstract}
Background: To determine a direct measure of publication bias by determining subsequent full-paper publication (P) of studies reported in animal research abstracts presented at an international conference (A).

Methods: We selected 100 random (using a random-number generator) A from the 2008 Society of Critical Care Medicine Conference. Using a data collection form and study manual, we recorded methodology and result variables from A. We searched PubMed and EMBASE to June 2015, and DOAJ and Google Scholar to May 2017 to screen for subsequent $\mathrm{P}$. Methodology and result variables were recorded from $\mathrm{P}$ to determine changes in reporting from $\mathrm{A}$. Predictors of $\mathrm{P}$ were examined using Fisher's Exact Test.

Results: $62 \%$ (95\% Cl 52-71\%) of studies described in A were subsequently $\mathrm{P}$ after a median 19 [IQR 9-33.3] months from conference presentation. Reporting of studies in A was of low quality: randomized 27\% (the method of randomization and allocation concealment not described), blinded 0\%, sample-size calculation stated 0\%, specifying the primary outcome $26 \%$, numbers given with denominators $6 \%$, and stating number of animals used $47 \%$. Only being an orally presented (vs. poster presented) A (14/16 vs. 48/84, $\mathrm{p}=0.025)$ predicted P. Reporting of studies in P was of poor quality: randomized 39\% (the method of randomization and allocation concealment not described), likely blinded $6 \%$, primary outcome specified $5 \%$, sample size calculation stated $0 \%$, numbers given with denominators $34 \%$, and number of animals used stated $56 \%$. Changes in reporting from A to P occurred: from non-randomized to randomized $19 \%$, from non-blinded to blinded $6 \%$, from negative to positive outcomes $8 \%$, from having to not having a stated primary outcome $16 \%$, and from non-statistically to statistically significant findings $37 \%$. Post-hoc, using publication data, $\mathrm{P}$ was predicted by having positive outcomes (published 62/62, unpublished 33/38; $p=0.003$ ), or statistically significant results (published 58/62, unpublished 20/38; $p<0.001$ ).
\end{abstract}

Conclusions: Only 62\% (95\% Cl 52-71\%) of animal research A are subsequently P; this was predicted by oral presentation of the A, finally having positive outcomes, and finally having statistically significant results. Publication bias is prevalent in critical care animal research.

Keywords: Animal experimentation, Bias (epidemiology), Intensive care, Publication bias

\section{Background}

Publication bias (PB) refers to preferential publication of research findings that have statistically significant positive outcomes [1]. This is problematic because the

\footnotetext{
*Correspondence: ari.joffe@ahs.ca

${ }^{4}$ 4-546 Edmonton Clinic Health Academy, 1140587 Avenue, Edmonton, AB T6G 1C9, Canada

Full list of author information is available at the end of the article
}

published literature is what scientists and clinicians use to inform their research and clinical practice. Indeed, the enterprise of evidence based medicine rests on the assumption that the published literature is an accurate representation of the current knowledge base. If evidence from systematic literature reviews is a biased representation of knowledge, this is a heavy blow to the paradigm of evidence based medicine [2]. The problem of $\mathrm{PB}$ is well recognized in clinical research; reviews 
suggest that only about half of research is published, and positive findings are a strong predictor of publication $[3,4]$.

Biomedical animal research (AR) is used to inform human research and practice on the assumption that animals are causal analogical models of human physiology and response to drugs and disease [5]. If $\mathrm{PB}$ is prevalent in $A R$, this is problematic for several reasons. First, evidence from published AR would be a biased representation of pre-clinical knowledge and thus be potentially misleading and dangerous for informing human medicine $[6,7]$. Second, the moral permissibility of AR, based on the claim that the harm to sentient animals used in AR is outweighed by large human benefit from this AR would be unacceptably weakened [8]. For example, animals harmed in unpublished AR cannot contribute to biomedical knowledge, and thus were harmed for no good reason. Moreover, the animals used in unpublished AR that had negative findings were harmed with additional potential harm also to humans, due to subsequent biomedical research and practice following false leads or safety data from the published AR [9]. Some data indirectly suggests PB in AR is common. Using statistical tools that examine small study bias (a larger effect size in small studies compared to larger studies), several AR reviews suggest PB occurs [10-17]. Another recent study found AR suffers from excess significance bias, again indirectly suggesting PB [18]. Of 174 basic science study abstracts submitted to a major gastroenterology conference, of which 90 were "animal studies", subsequent publication occurred for $47 \%$, with no statistically significant predictors of publication found; however, results for AR were not reported separately [19]. To our knowledge there has not been a direct assessment of whether PB occurs in AR.

Here we aimed to determine whether AR abstracts presented at an international critical care conference are subsequently published in the peer-reviewed literature, and what the predictors of subsequent publication may be. We chose critical care because inducing critical illness may be one of the most invasive fields of AR. In addition, our method allows a direct assessment of PB of AR that has reached the stage of warranting presentation to peers.

\section{Methods}

\section{Ethics statement}

The University of Alberta Health Research Ethics Board waived the requirement for review or consent because the study involved only publicly available data, and no individual that would require consent to participation.

\section{Abstract review}

We reviewed 100 random published abstracts of $\mathrm{AR}$ from the 2008 Society of Critical Care Medicine international conference [20]. The abstracts were chosen using a random number generator. There were no restrictions other than that the abstract reported an AR experiment, defined as: a procedure for collecting scientific data on the response to an intervention in a systematic way to maximize the chance of answering a question correctly or to provide material for the generation of new hypotheses [21]. If there was any doubt about inclusion, this was discussed among the two authors to achieve consensus. A data collection form and instruction manual (see Additional files 1,2) were created based on published Canadian (the Canadian Council on Animal Care in science guidelines "Choosing an appropriate endpoint in experiments using animals for research, teaching and testing" and "Animal use protocol review"), United States (the Institute for Laboratory Animal Research, National Research Council "Guidance for the description of animal research in scientific publications"), and United Kingdom (the National Center for the 3Rs "Animal Research: Reporting of In Vivo Experiments" ARRIVE guidelines) recommendations for reporting AR [22-25]. These guidelines were used as they are comprehensive, well referenced, readily available, and based upon literature review. For example, the ARRIVE guidelines were developed to improve the quality of reporting AR, and are endorsed by over 100 journals from all over the world [22]. Data were obtained for factors important to methodological quality.

The data collection form was completed for all 100 critical care AR (using mammals) abstracts. Both authors independently completed forms for the first 10 abstracts, discussing the data after every fifth abstract until consistent agreement was obtained. Thereafter, one author completed forms on all abstracts, and the other author independently did so for every fifth abstract (with discussion of the data to maintain consistent agreement), and for any data considered uncertain (with discussion until consensus). The instruction manual made clear definitions for all data collection; for example, a sample size calculation was defined as describing, for the primary outcome, a p value (alpha), power (1-beta), and minimally important difference (the difference between groups that the study is powered to detect).

\section{Search for publication}

After the abstract data was finalized in the data collection form, we searched both PubMed and EMBASE to determine subsequent publication of the data presented in the abstracts. The search strategy was defined in the instruction manual. We searched for the first, second, or last 
author; and at least two MeSH subject terms (e.g., acute lung injury, or sepsis). The search strategy was developed to be as inclusive as possible, by using the operator "OR" between the authors searched and between the $\mathrm{MeSH}$ terms used. Abstracts that were later published as only a small part of a larger study were considered published. All titles and abstracts of identified publications were reviewed to determine if they reported the study from the abstract. To be considered publication of the abstract results the published paper needed to report the same experiment, and we included the publication even if more animals were used and/or more experiments were done than reported in the abstract. If there was any doubt, both authors together discussed the titles and abstracts and reached consensus. If publication could not be found by one of the authors, the second author also independently searched to confirm this; if publication was then found, both authors discussed the finding and reached consensus. The search was done from 2007 (up to 14 months prior to the conference date) to June 2015 (up to 86 months after the conference date) inclusive.

In response to an anonymous reviewer, in May 2017 one author (ARJ) searched DOAJ (the Directory of Open Access Journals) and Google Scholar for subsequent publication of any of the abstracts determined unpublished by the above strategy. The search strategy was modified to be consistent with the PubMed and EMBASE searches. On DOAJ we searched separately for each of the first or last author, and if more than 30 publications were listed, we added (separately, one at a time) each of two subject terms from the abstract title. On Google Scholar we searched for each of the first or last author, added (separately, one at a time) each of two subject terms from the abstract title into the "contains all of the words" box, and limited the search to from years 2007 to 2017. We screened all returned titles, and if necessary, abstracts and full text, up to and including 5 pages of each search result.

Finally, as suggested by another reviewer, we emailed an author of each unpublished abstract to ask if the abstract had been published in full, and if so, to provide the citation. For each abstract, one author (ARJ) searched PubMed for the abstract author (starting with first author, and if no email found, last author, second author, second last author, etc.) in order to obtain a corresponding author email address. To be sure this was a current email for the correct abstract author, the address was to be from a publication since 2010, and on a topic related to the abstract, preferably with a same coauthor(s) as in the abstract. If the email was returned undeliverable, the search was repeated to obtain another of the abstract authors' email. For the 3 emails that remained undeliverable we identified a current corresponding co-author of a publication with the target author, and asked this contact to forward the request.

\section{Publication review}

A data collection form and instruction manual (see Additional files 1,2) were used for each identified publication. Both authors independently completed data collection forms for the first 5 identified publications, discussing the data until consistent agreement was obtained. Thereafter, one author completed forms on all publications, and the other author independently did so for every fifth publication (with discussion of the data to maintain consistent agreement), and for any data considered uncertain (with discussion until consensus). The instruction manual made clear definitions for all data collection variables.

\section{Statistics}

Data are presented using descriptive statistics, and were analyzed using SPSS. The primary outcome was prespecified as subsequent publication of AR abstracts, with 95\% adjusted Wald Confidence Intervals (CI). Assuming the subsequent publication rate of AR will be similar to that for clinical research weighted mean full publication rate of 44.5\% (95\% CI 43.9-45.1\%) [3], an abstract sample of $n=80$ will provide reasonable $95 \%$ CI of $\pm 10 \%$. Thus, we decided to include 80 abstracts, and if the timing allows, add a random sample of 20 abstracts to increase the sample size prior to any data analysis. We compared abstracts that were published to those that were not using Chi square and Fisher's Exact test, with statistical significance accepted at $\mathrm{p}<0.05$ without correction for multiple comparisons. Pre-defined possible predictors included methodology (randomization, blinding, sample size calculation, primary outcome specification, results reported with denominators, number of animals used stated), ethical (number of animals used $>19$, highest species used rodent vs other), outcome (positive finding, statistically significant finding), and type of animal model (sepsis, drug used, surgery performed, animals stated to be killed) variables. Post-hoc we tested for possible predictors including methodology (randomization, blinding) and outcome (positive finding, statistically significant finding) variables updated with information from publication if available. We also determined whether there were changes in important information reported between the abstract and subsequent publication, using our a priori definitions in the data collection form and instruction manual.

\section{Results}

\section{Primary outcome}

61 [61\% (95\% CI 51-70\%)] abstracts were subsequently published after a median 19 [IQR 9-33, range 0-68] 
months by searching PubMed and EMBASE. The search of DOAJ found no publications, and Google Scholar found one further publication, for a publication rate of $62 \%$ (95\% CI 52-71\%). Publication was usually within 3 years; months to publication was mean 22.6 (SD 17.1), median 19 [IQR 9, 33.3], range 0-68 months; the 80th percentile was 35 months (2.9 years); 90th percentile 52 months (4.3 years); and 95th percentile 60 months (5 years).

Emails were sent on May 25 (and to non-responders again on June 1) to an abstract author for the initially determined 39 unpublished abstracts. There were 13 replies by June 8 (within 2 weeks): 9 confirmed non-publication, and 4 claimed publication. However, the citations provided in the 4 clearly did not match the abstract methodology despite being on a similar topic (1 was published 4 years before the abstract and used different study interventions; 1 was a global head injury model whereas the abstract was of a focal brain injury model; 1 randomized to different intervention groups than in the abstract; and 1 was published 12 years before the abstract and used a different animal model). Thus, no publication was identified by this emailing strategy.

\section{Predictors of abstract publication}

The differences between published and unpublished abstracts are given in Table 1. Methodological quality of reporting in the abstracts was poor, with randomization in 27 (27\%; none reported the method of randomization or allocation concealment), blinding in $0(0 \%)$, sample

Table 1 Potentially predictive variables for subsequent publication of abstracts presented at an international critical care conference

\begin{tabular}{|c|c|c|c|}
\hline Potential predictor variable & Published $(n=62)$ & Non-published $(\mathrm{n}=38)$ & p value ${ }^{a}$ \\
\hline \multicolumn{4}{|l|}{ Type of presentation } \\
\hline Oral (vs. poster) presentation & $14(23 \%)$ & $2(5 \%)$ & 0.025 \\
\hline Research location in North Americab & $40(65 \%)$ & $31(82 \%)$ & 0.075 \\
\hline \multicolumn{4}{|l|}{ Methodological quality variables } \\
\hline Randomized & $17(27 \%)$ & $10(26 \%)$ & 0.99 \\
\hline Blinded & $0(0 \%)$ & $0(0 \%)$ & - \\
\hline Primary outcome given & $13(21 \%)$ & $13(34 \%)$ & 0.16 \\
\hline Numbers with denominators & $4(6 \%)$ & $2(5 \%)$ & 0.99 \\
\hline Number of animals stated & $30(48 \%)$ & $17(45 \%)$ & 0.84 \\
\hline Sample size calculation & $0(0 \%)$ & $0(0 \%)$ & - \\
\hline \multicolumn{4}{|l|}{ Ethical quality variables } \\
\hline Highest species rodent ${ }^{c}$ & $35(56 \%)$ & $26(68 \%)$ & 0.23 \\
\hline$>19$ animals used & $15 / 30(50 \%)$ & $5 / 17(29 \%)$ & 0.14 \\
\hline \multicolumn{4}{|l|}{ Outcome variables } \\
\hline Main outcomes positive & $57(92 \%)$ & $33(87 \%)$ & 0.50 \\
\hline Statistically significant result & $35(56 \%)$ & $20(53 \%)$ & 0.71 \\
\hline \multicolumn{4}{|l|}{ Type of animal model } \\
\hline Sepsis & $27(44 \%)$ & $13(34 \%)$ & 0.41 \\
\hline Drug used & $24(39 \%)$ & $15(39 \%)$ & 0.99 \\
\hline Surgery performed & $25(40 \%)$ & $13(34 \%)$ & 0.67 \\
\hline Animals stated to be killed & $34(55 \%)$ & $21(55 \%)$ & 0.99 \\
\hline Potential predictor variable & Data in publication $(n=62)$ & Data in abstract $(\mathrm{n}=38)$ & $\mathrm{p}$ value \\
\hline \multicolumn{4}{|l|}{ Post-hoc comparisons } \\
\hline \multicolumn{4}{|l|}{ Indicators of publication bias } \\
\hline Main outcomes positive & $62(100 \%)$ & $33(87 \%)$ & 0.003 \\
\hline Statistically significant result & $58(94 \%)$ & $20(53 \%)$ & $<0.001$ \\
\hline \multicolumn{4}{|l|}{ Indicators of methodological quality } \\
\hline Randomized & $24(39 \%)$ & $10(26 \%)$ & 0.20 \\
\hline Blinded & $4(6 \%)$ & $0(0 \%)$ & 0.080 \\
\hline
\end{tabular}

a Comparisons made using Fisher's Exact or Chi square test

b Asia 17 (17\%); North America 71 (71\%), Europe 15 (15\%); Australia/New Zealand 1 (1\%), and Africa or South America 0

c Species used were: rodent (61), rabbit (2), farm animal (35), primate (1), other (1: not stated) 
size calculation in $0(0 \%)$, primary outcome stated in 26 (26\%), number with denominators given for main outcomes in $6(6 \%)$, and number of animals used stated in 47 (47\%; median 18, IQR 11-24, range 1-60; total 957). Most abstracts reported mainly positive outcomes (90, $90 \%$ ), and these outcomes were statistically significant in 55 (55\%). The only statistically significant predictor of subsequent publication was being an oral presentation at the conference $(\mathrm{p}=0.024)$.

\section{Changes from abstract to publication}

Changes in reporting between the abstract and publication are given in Table 2. The reported methodological quality of publications was poor: randomized in 24 (39\%; method of randomization and allocation concealment not reported), blinding in 4 (6\%; it was unclear for which outcomes blinding occurred in all of these), sample size calculation in $0(0 \%)$, primary outcome stated in $3(5 \%)$, numbers given with denominators in results $21(34 \%)$, and number of animals stated in 35 (56\%; median 20 , IQR $14-35$, range 5-125, total 993). Changes in reporting between abstract and publication included: from non-randomized in the abstract to randomized in the publication for 12 (19\%), from no mention of blinding to blinding for some outcomes in 4 (6\%), from having a primary outcome in the abstract to no primary outcome stated in the publication for $10(16 \%$; this is for $10 / 13$,
$77 \%$ of the abstracts that stated a primary outcome), from main outcomes being negative in the abstract to being positive (or excluded) in the publication for $5(8 \%)$, and from main outcomes being non-statistically significant (or no statistical significance stated) in the abstract to being statistically significant in the publication for 23 (37\%). In the publications the main outcomes reported from the abstract were positive for $62(100 \%)$, and statistically significantly so for 58 (94\%).

\section{Post-hoc predictors of subsequent publication}

Given the unexpected changes from abstract to publication, we determined predictors for subsequent publication using updated numbers combining abstract and publication (when available) data (Table 1). The methodological variables of randomization or blinding did not predict publication, but finally having main outcomes being positive $(\mathrm{p}=0.003)$, and finally having statistically significant main outcomes $(\mathrm{p}<0.001)$ were predictors of publication.

\section{Post-hoc comparison of oral versus poster presentations}

Given that oral presentation was a possible predictor of subsequent publication $(\mathrm{p}=0.025)$, we compared oral to poster presentations on quality of abstracts and publications (Table 3). Orally presented abstracts were less likely to report animal numbers $(\mathrm{p}=0.02)$ and randomization

Table 2 Changes in reporting from abstract to subsequent publication of animal research presented at an international critical care conference

\begin{tabular}{|c|c|c|c|}
\hline Variable & $\begin{array}{l}\text { Prevalence } \\
\text { in abstracts } n=100\end{array}$ & $\begin{array}{l}\text { Prevalence } \\
\text { in publications } n=62\end{array}$ & Change from abstract $(A)$ to publication $(P)$ \\
\hline Randomized & $27(27 \%)$ & $24(39 \%)$ & 12/62 (19\%): non-R in A; R in P \\
\hline Method of randomization & $0(0 \%)$ & $0(0 \%)$ & $0(0 \%)$ \\
\hline Allocation concealment & $0(0 \%)$ & $0(0 \%)$ & $0(0 \%)$ \\
\hline Blinding (possible) & $0(0 \%)$ & $4(6 \%)$ & 4/62 (6\%): no mention in A; blinding of some outcomes in P \\
\hline Sample size calculation & $0(0 \%)$ & $0(0 \%)$ & $0(0 \%)$ \\
\hline Primary outcome stated & $26(26 \%)$ & $3(5 \%)$ & $\begin{array}{l}\text { 10/62 (16\%): } 9 \text { stated in A, not stated in } \mathrm{P} ; 1 \text { stated primary } \\
\text { outcome was different between A and P }\end{array}$ \\
\hline Numbers with denominators & $6(6 \%)$ & $21(34 \%)$ & 17/62 (27\%): no denominators in A; denominators in P \\
\hline Main outcomes positive & $90(90 \%)$ & $62(100 \%)$ & 5/62 (8\%): negative in A; positive (or excluded) in P \\
\hline Number of animals stated ${ }^{\mathrm{a}}$ & $47(47 \%)$ & $35(56 \%)$ & $\begin{array}{l}\text { 13/62 (21\%): in the } \mathrm{P} \text { the number was smaller in } 3(5 \%) \text { and } \\
\text { larger in } 10(16 \%)\end{array}$ \\
\hline $\begin{array}{l}\text { Statistically significant result of } \\
\text { main outcomes }{ }^{\text {b }}\end{array}$ & $55(55 \%)$ & $58(94 \%)$ & 23/62 (37\%): not significant (or not stated) in A; significant in P \\
\hline \multicolumn{4}{|l|}{$A$ abstract, $P$ publication, $R$ randomized } \\
\hline \multicolumn{4}{|c|}{$\begin{array}{l}\text { In abstract: median } 18 \text { [IQR 11-24] (range 1-60), total } 957 \text { animals used. In publication: median } 20 \text { [IQR 14-35] (range 5-125), total 993 animals used. When smaller } \\
\text { in publication: by 3, 4, and } 6 \text { animals. When larger in publication: by median } 14 \text { [IQR 5-25] range 4-54, total } 213 \text { animals. Reasons for change in number were due to: } \\
\text { new control group (1), different numbers in both control and intervention group (9), different numbers in the only group in the study (1), new reason animals required } \\
\text { (2), or not clear (1) }\end{array}$} \\
\hline \multicolumn{4}{|c|}{$\begin{array}{l}\text { b In the } 23 \text { that changed in statistical significance from A to P: the animal numbers did not change in } 5 \text { [these numbers did change in } 4 \text { (larger number in } 2 \text {, and } \\
\text { smaller number in 2), and change could not be determined in the rest because numbers were not stated in P in } 9 \text {, and were not stated in the } A \text { in } 5 \text { ]; the main } \\
\text { outcomes changed in } 2 \text {; and denominators changed in } 3 \text { [change could not be determined in } 19 \text { others because denominators were not reported; thus we could be } \\
\text { sure that denominators did not change in only 1] }\end{array}$} \\
\hline
\end{tabular}


$(\mathrm{p}=0.06)$ than poster presented abstracts, and orally presented abstracts that were subsequently published remained less likely to report animal numbers and randomization than poster presentations that were subsequently published.

\section{Post-hoc comparison of abstracts and publications according to journal impact factor}

Given the lack of methodological differences between published and unpublished abstracts, as suggested by a reviewer, we compared quality between lower (at or below median) and higher (above median) journal impact factor publications. There were no statistically significant differences in abstract quality between those subsequently published in lower vs higher impact journals
(Table 4). The only statistically significant difference in quality between publications in lower vs higher impact journals was in blinding for some outcomes, which was used in $0 \%$ of lower impact publications and $4(13 \%)$ of higher impact publications $(\mathrm{p}=0.049)$.

\section{Discussion}

There are several important findings from this study. First, only $62 \%$ (95\% CI $52-71 \%$ ) of AR abstracts presented at an international critical care conference, the Society for Critical Care Medicine 2008 Conference, were subsequently published. This means that much AR that is ready for presentation to peers does not contribute to the biomedical literature. Second, predictors of publication were oral presentation, and finally having positive

Table 3 Post-hoc comparison of oral versus poster abstracts and publications

\begin{tabular}{|c|c|c|c|}
\hline Abstract variables & Oral $(n=16)$ & Poster $(n=84)$ & $\mathrm{p}$ value \\
\hline Research location in North America & $14(88 \%)$ & $57(68 \%)$ & 0.14 \\
\hline \multicolumn{4}{|l|}{ Methodological quality } \\
\hline Randomized & $1(6 \%)$ & $26(31 \%)$ & 0.06 \\
\hline Primary outcome given & $2(13 \%)$ & $24(29 \%)$ & 0.23 \\
\hline Numbers with denominators & $0(0 \%)$ & $6(7 \%)$ & 0.59 \\
\hline \multicolumn{4}{|l|}{ Ethical quality } \\
\hline Highest species rodent & $13(81 \%)$ & $48(57 \%)$ & 0.07 \\
\hline Number of animals stated & $3(19 \%)$ & $44(52 \%)$ & 0.02 \\
\hline Number of animals used & 28 (SD 17) & 29 (SD 12) & 0.27 \\
\hline \multicolumn{4}{|l|}{ Outcomes } \\
\hline Main outcomes positive & $16(100 \%)$ & $74(88 \%)$ & 0.36 \\
\hline Statistically significant result & $9(56 \%)$ & $46(55 \%)$ & 0.95 \\
\hline \multicolumn{4}{|l|}{ Type of animal model } \\
\hline Sepsis & $8(50 \%)$ & $52(62 \%)$ & 0.41 \\
\hline Drug used & $8(50 \%)$ & $53(63 \%)$ & 0.40 \\
\hline Surgery & $11(69 \%)$ & $51(61 \%)$ & 0.59 \\
\hline Publication variables & Oral published $(n=14)$ & Poster published $(n=48)$ & p value \\
\hline \multicolumn{4}{|l|}{ Methodological quality } \\
\hline Randomized & $1(7 \%)$ & $23(48 \%)$ & 0.006 \\
\hline Blinded & $0(0 \%)$ & $4(8 \%)$ & 0.57 \\
\hline Primary outcome given & $0(0 \%)$ & $3(6 \%)$ & 0.99 \\
\hline Numbers with denominators & $3(21 \%)$ & $18(38 \%)$ & 0.35 \\
\hline \multicolumn{4}{|l|}{ Ethical quality } \\
\hline Number of animals stated & $4(29 \%)$ & $31(65 \%)$ & 0.03 \\
\hline Number of animals used & 46 (SD 55) & 26 (SD 19) & 0.53 \\
\hline \multicolumn{4}{|l|}{ Outcomes } \\
\hline Main outcomes positive & $14(100 \%)$ & $48(100 \%)$ & 0.99 \\
\hline Statistically significant result & $13(93 \%)$ & 45 (94\%) & 0.99 \\
\hline \multicolumn{4}{|l|}{ Journal factors } \\
\hline Journal impact factor & $5.1(\mathrm{SD} 3.2)$ & $5.3(\mathrm{SD} 5.3)$ & 0.92 \\
\hline Months to publication & 31 (SD 23) & 20 (SD 14) & 0.12 \\
\hline
\end{tabular}

Comparisons made using Fisher's Exact or Chi square test, or independent samples student $t$ test, as appropriate 
Table 4 Post-hoc comparison of abstracts that were subsequently published in lower versus higher impact journals

\begin{tabular}{|c|c|c|c|}
\hline Potential predictor variable & Published in lower impact $(n=32)$ & Published in higher impact $(n=30)$ & p value ${ }^{a}$ \\
\hline \multicolumn{4}{|l|}{ Type of presentation } \\
\hline Oral (vs. poster) presentation & $7(22 \%)$ & $7(23 \%)$ & 0.99 \\
\hline Research location in North America & $17(53 \%)$ & $23(77 \%)$ & 0.07 \\
\hline \multicolumn{4}{|l|}{ Methodological quality variables } \\
\hline Randomized & $7(22 \%)$ & $10(33 \%)$ & 0.40 \\
\hline Blinded & $0(0 \%)$ & $0(0 \%)$ & - \\
\hline Primary outcome given & $6(19 \%)$ & $7(23 \%)$ & 0.76 \\
\hline Numbers with denominators & $1(3 \%)$ & $3(10 \%)$ & 0.35 \\
\hline Number of animals stated & $14(44 \%)$ & $16(53 \%)$ & 0.61 \\
\hline Sample size calculation & $0(0 \%)$ & $0(0 \%)$ & - \\
\hline \multicolumn{4}{|l|}{ Ethical quality variables } \\
\hline Highest species rodent & $20(63 \%)$ & $15(50 \%)$ & 0.32 \\
\hline$>19$ animals used & $6(19 \%)$ & $9(30 \%)$ & 0.30 \\
\hline \multicolumn{4}{|l|}{ Outcome variables } \\
\hline Main outcomes positive & $28(88 \%)$ & $29(97 \%)$ & 0.36 \\
\hline Statistically significant result & $17(53 \%)$ & $18(60 \%)$ & 0.59 \\
\hline \multicolumn{4}{|l|}{ Type of animal model } \\
\hline Sepsis & $9(28 \%)$ & $18(60 \%)$ & 0.02 \\
\hline Drug used & $14(44 \%)$ & $10(33 \%)$ & 0.44 \\
\hline Surgery performed & $12(38 \%)$ & $13(43 \%)$ & 0.80 \\
\hline Animals stated to be killed & $19(59 \%)$ & $15(50 \%)$ & 0.61 \\
\hline
\end{tabular}

a Comparisons made using Fisher's Exact or Chi square test. For published articles, the journal impact factors were: mean 5.2 (SD 4.9), median 4.5 [IQR 2.4, 7.4$]$, range $0.02-30.36 ; 5$ articles were published in journals with impact factor $>10$

outcomes and statistically significant results. Orally presented abstracts were not of higher methodological or ethical quality. These predictors confirm that much of the reason for non-publication is due to $\mathrm{PB}$, which leads to a biased representation of biomedical research in the published literature. This is the first study of which we are aware to directly confirm PB in the AR literature. Third, the reported methodological quality of abstracts and publications is poor, particularly due to no mention of method of randomization, allocation concealment, or sample size calculation, and infrequent mention of randomization, primary outcomes, number of animals used, and numbers with denominators provided for results. This suggests that even published AR has poor internal validity. That the methodological quality did not differ between abstracts and publications suggests that this quality was not a determinant of acceptance for publication. Moreover, quality did not differ between abstracts subsequently published in higher versus lower impact journals. Finally, the change in reporting from abstract to publication is of concern. Although infrequent, the increase in reporting of randomization (by 19\%) and blinding (by 6\%), the decrease in reporting of a primary outcome (by $16 \%$ ), and the increase in positive findings (by $8 \%$ ) and statistically significant findings (by 37\%) suggest that in published AR there may be selective analysis and outcome reporting bias that aims to find reportable results. The change in numbers of animals reported from abstract to publication in 13/35 (37\%) of those studies reporting animal numbers [in the publication the number was smaller in $3(9 \%)$ and larger in $10(29 \%)$ ] also suggests the possibility of checking the data during the ongoing study until a significant difference is found (i.e., repeated interim analyses of data as they accumulate). These changes were not significantly less frequent in publications in higher vs. lower impact factor journals (Table 5).

These findings are compatible with previous research. In clinical research, $\mathrm{PB}$ in reporting findings from abstracts presented at conferences has been well recognized; only about $45 \%$ of abstracts are subsequently published, and predictors of subsequent publication include positive and statistically significant findings [2-4]. In addition, for clinical research, the quality of poster and orally presented abstracts has been similar [26]. Previous indirect assessments of PB in AR have suggested small study bias, and excess significance bias [10-18]. A survey of animal researchers in the Netherlands found that respondents estimated only $50 \%$ (95\% CI $32-70 \%$ ) "of ethics-approved experiments performed in experimental 
Table 5 Post-hoc comparison of reporting in publications, and changes in reporting from abstract to publication, according to journal impact factor

\begin{tabular}{|c|c|c|c|c|}
\hline Variable & $\begin{array}{l}\text { Prevalence in lower } \\
\text { impact } n=32\end{array}$ & $\begin{array}{l}\text { Prevalence in higher } \\
\text { impact } n=30\end{array}$ & $\begin{array}{l}\mathrm{p} \text { value of } \\
\text { comparison }\end{array}$ & Change from abstract $(A)$ to publication $(P)$ \\
\hline Randomized & $12(38 \%)$ & $12(40 \%)$ & 0.99 & \\
\hline Change from $A$ to $P$ & $8(25 \%)$ & $4(13 \%)$ & 0.25 & All 12: from non- $R$ in $A$, to $R$ in $P$ \\
\hline Method & $0(0 \%)$ & $0(0 \%)$ & - & - \\
\hline Allocation concealment & $0(0 \%)$ & $0(0 \%)$ & - & - \\
\hline Blinding (possible) & $0(0 \%)$ & $4(13 \%)$ & 0.049 & \\
\hline Change from $A$ to $P$ & $0(0 \%)$ & $4(13 \%)$ & 0.049 & $\begin{array}{l}\text { All 4: from no mention in A, to blinding of some } \\
\text { outcomes in P }\end{array}$ \\
\hline Sample size calculation & $0(0 \%)$ & $0(0 \%)$ & - & - \\
\hline Primary outcome stated & $3(9 \%)$ & $0(0 \%)$ & 0.09 & \\
\hline Change from $A$ to $P$ & $3(9 \%)$ & $6(20 \%)$ & 0.24 & All 9: state in A, to not stated in $P$ \\
\hline Numbers with denominators & $8(25 \%)$ & $13(43 \%)$ & 0.13 & \\
\hline Change from $A$ to $P$ & $6(19 \%)$ & $10(33 \%)$ & 0.19 & All 16: no denominators in $\mathrm{A}$, to denominators in $\mathrm{P}$ \\
\hline Main outcomes positive & $32(100 \%)$ & $30(100 \%)$ & - & \\
\hline Change from $A$ to $P$ & $4(13 \%)$ & $1(3 \%)$ & 0.19 & All 5: negative in $A$, to positive or excluded in $P$ \\
\hline Number of animals stated ${ }^{a}$ & $17(53 \%)$ & $18(60 \%)$ & 0.59 & \\
\hline Change from $A$ to $P$ & $6(19 \%)$ & $7(23 \%)$ & 0.66 & $\begin{array}{l}\text { From } A \text { to } P \text { the number was smaller in } 3(9 \%) \text { and } \\
\text { larger in } 10(29 \%)^{\mathrm{a}}\end{array}$ \\
\hline $\begin{array}{l}\text { Statistically significant result } \\
\text { of main outcomes }\end{array}$ & $30(94 \%)$ & $28(93 \%)$ & 0.95 & \\
\hline Change from $A$ to $P$ & $13(41 \%)$ & $10(33 \%)$ & 0.55 & $\begin{array}{l}\text { All 23: not significant (or not stated) in A, to signifi- } \\
\text { cant in } \mathrm{P}^{\mathrm{b}}\end{array}$ \\
\hline Months to publication & 27 (SD 17) & 18 (SD 16) & 0.02 & - \\
\hline
\end{tabular}

Comparisons made using Fisher's Exact or Chi square test, or independent samples student $\mathrm{t}$ test, as appropriate

$A$ abstract, $P$ publication, $R$ randomized

a In the 13 that changed in animal numbers from $A$ to $P$ : in the lower and higher impact $P$ the number was smaller in 1 (by $n=4$ ) and 2 (by $n=3$ and 6 ), and larger in 5 (by $n=4,14,36,52,54$ ) and 5 (by $n=4,5,7,22,25$ ) respectively

b In the 23 that changed in statistical significance from $A$ to $P$, in the lower and higher impact $P$ respectively: the animal numbers did not change in 4 and 1 ( $p=0.19$ ) [these numbers did change in 2 and 2 (larger number in 2, and smaller number in 2), and change could not be determined in the rest because numbers were not stated in $P$ in 6 and 3, and were not stated in the $A$ in 1 and 4]; the main outcomes changed in 2 and $0(p=0.16)$; and denominators changed in 1 and 2 ( $p=0.52$ ) [change could not be determined in 19 others because denominators were not reported in 11 and 8 ; thus we could be sure that denominators did not change in 1]

animal research is published," well within our 95\% CI of publication rate [27]. Many previous reviews have found poor methodological quality of reported AR, including in the field of critical care [28-33]. Although selective analysis and outcome reporting bias, and data "peaking" to find significant results (instead of pre-defined sample sizes being calculated) have been suspected in AR by commentators, this is the first confirmation of this occurring as far as we are aware $[6,7,18,34]$.

These findings are important for several reasons. In clinical research PB poses a serious threat to validly assessing the effectiveness of new therapies in systematic reviews; research subjects have participated in a study without (or even negatively) contributing to science; and those who make health care decisions are faced with a biased subset of scientific evidence [2-4]. PB in preclinical AR is important for the same reasons; indeed, $A R$ is often used to guide decisions for further $A R$ and for human clinical research, and the ethical justification for AR is exactly this contribution to making decisions of benefit for human clinical research and treatment [2, $6,7,9]$. The finding of $\mathrm{PB}$ in AR suggests that the valid extrapolation of findings from the AR literature to inform research and treatment in humans is seriously threatened. There are several important implications. First, strategies to combat $\mathrm{PB}$ are a priority. For example, funding agencies that support AR could tie funding to subsequent full publication of results, and academic institutions that employ scientists doing AR could tie full publication of results to academic review [2]. In addition, journal editors and referees have a responsibility to publish negative results, if of good quality. Second, strategies to identify $\mathrm{PB}$ are a priority, for example, international registration of AR protocols $[2,6,7]$. Third, attention to methodological quality requirements in funding, ethics review, and academic review decisions is a priority [28-33]. For 
example, if sample size calculations and statistical design for primary outcomes are required in protocols and grant applications, this can prevent data dredging, selective outcome reporting bias, ongoing recruitment aiming to obtain statistically significant outcomes, and other biases [35].

There are limitations to this study. First, it is possible that some abstracts were published but this was not detected by our search strategy. Second, it is also possible that methodological quality was better than reported, particularly in abstracts where space limitations are restrictive. We believe that this explanation is problematic. Optimal methods of randomization, allocation concealment, and blinding (of the experiments and assessment of their outcomes) are time consuming and expensive to implement. Randomization, blinding, sample size calculation for a pre-specified primary outcome (limiting "sampling to a foregone conclusion" and multiple statistical testing for post-hoc outcomes), and describing research subject numbers (including attrition or exclusion of animals) markedly improve the quality, validity, and reproducibility of even preliminary experimental results. Not reporting this information can make published findings unreliable, regardless of whether the information was in fact known to the authors. This is why guidelines for reporting clinical research in conference abstracts include these points in their minimal standards [36-38]. This is also in the spirit of the ARRIVE guidelines, meant to ensure publications are "'fit for purpose,' meaning that incomplete reporting of relevant information effectively renders many publications of limited value as instruments to inform policy or clinical and scientific practice... unusable due to poor reporting." [22] These points are also in the "core set of research parameters" in the US National Institute of Neurological Disorders and Stroke workshop statement, those "that should be addressed when reporting the results of animal experiments... that would allow informed judgment about the findings" [32]. Third, the sample size of 100 abstracts and 62 publications limits study power to detect predictors of publication, or of publication in lower versus higher impact journals. The analyses of predictors should be considered exploratory only, particularly given the multiple statistical testing. Fourth, this study is limited to abstracts reported at one international conference, and in the field of critical care, and may not generalize to other conferences and fields. Finally, we did not assess the quality of statistical methods used; however, this may not be possible given that most animal research publications examine statistically well over 20 outcomes [28].

Nevertheless, the strengths of this study mitigate some of these concerns. This study was done with clear data definitions and a data collection form, and with a clear rigorous search strategy used by two authors independently. In addition, the field of critical care AR usually involves quite invasive management of animals (e.g., invasive procedures done for animal monitoring, and invasive study interventions such as surgery and ventilation), and therefore might be expected to be most likely to be reported and done to high standards [28]. Finally, the results are similar to many previous reports suggesting $\mathrm{PB}$ in clinical and $\mathrm{AR}$, and reports regarding the methodological quality of AR [2-4, 6, 7, 10-18, 27-33]. Our method of determining $\mathrm{PB}$, that is, by determining subsequent publication of data presented in abstract form at an international conference, has been widely accepted in clinical research $[3,4]$.

\section{Conclusions}

A direct assessment of subsequent publication of AR presented as abstracts at an international critical care conference confirms PB is prevalent. This is of concern because it suggests that published AR is a biased representation of research findings, and that animals are harmed without benefit, and with potential harm (misleading literature reviews), to humans. If AR has any chance of translating to human medicine addressing this problem of $\mathrm{PB}$ must be a high priority for researchers, funders, journals, and clinicians alike $[39,40]$.

\section{Additional files}

Additional file 1. The case report form for the study.

Additional file 2. The study manual. This file provides the definitions used, and the details of methods for performing this study.

Abbreviations

AR: animal research; PB: publication bias.

\section{Authors' contributions}

ARJ contributed to conception and design, acquisition, analysis and interpretation of data, and drafted the paper, and read and had final approval of the version to be published. UC contributed to design, acquisition and interpretation of data, and revising the manuscript critically for intellectual content, and read and had final approval of the version to be published. ARJ had full access to all the data in the study and takes responsibility for the integrity of the data and the accuracy of the data analysis. Both authors read and approved the final manuscript.

\section{Author details}

${ }^{1}$ Faculty of Science, University of Alberta, Edmonton, Canada. ${ }^{2}$ Faculty of Medicine, Department of Pediatrics, Stollery Children's Hospital, University of Alberta, Edmonton, AB, Canada. ${ }^{3}$ John Dossetor Health Ethics Center, University of Alberta, Edmonton, AB, Canada. ${ }^{4}$ 4-546 Edmonton Clinic Health Academy, 1140587 Avenue, Edmonton, AB T6G 1C9, Canada.

\section{Acknowledgements}

Not applicable.

Competing interests

The authors declare that they have no competing interests. 


\section{Availability of data and materials}

The dataset analyzed during the current study are available from the corresponding author on reasonable request.

\section{Ethics approval and consent to participate}

The University of Alberta Health Research Ethics Board waived the requirement for review or consent because the study involved only publicly available data, and no individual that would require consent to participation.

\section{Funding}

UC was supported for this research by a University of Alberta Office of the Provost and VP (Academic) Summer Research Award; the funding agency had no role in the design and conduct of the study; collection, management, analysis or interpretation of the data; preparation, review, or approval of the manuscript; or the decision to submit the manuscript for publication.

\section{Publisher's Note}

Springer Nature remains neutral with regard to jurisdictional claims in published maps and institutional affiliations.

Received: 20 October 2016 Accepted: 28 June 2017

Published online: 07 July 2017

\section{References}

1. Guyatt GH, Oxman AD, Montori V, Vist G, Kunz R, Brozek J, et al. GRADE guidelines: 5. Rating the quality of evidence-publication bias. J Clin Epidemiol. 2011;64(12):1277-82

2. Chan A, Song F, Vickers A, Jefferson T, Dickersin K, Gotzsche PC, et al. Increasing value and reducing waste: addressing inaccessible research. Lancet. 2014;383(9913):257-66.

3. Scherer RW, Langenberg P, von Elm E. Full publication of results initially presented in abstracts. Cochrane Database Syst Rev. 2007;2:MR000005. doi:10.1002/14651858.MR000005.pub3.

4. Song F, Parekh-Bhurke S, Hooper L, Loke YK, Ryder JJ, Sutton AJ, Hing CB, Harvey I. Extent of publication bias in different categories of research cohorts: a meta-analysis of empirical studies. BMC Med Res Methodol. 2009:9:79.

5. Greek R, Rice MJ. Animal models and conserved processes. Theor Biol Med Model. 2012;9:40

6. van der Worp HB, Howells DW, Sena ES, Porritt MJ, Rewell S, O'Collins V, Macleod MR. Can animal models of disease reliably inform human studies? PLoS Med. 2010;7(3):e1000245.

7. Green SB. Can animal data translate to innovations necessary for a new era of patient-centred and individualized healthcare? Bias in preclinical animal research. BMC Med Ethics. 2015;15:53.

8. Garrett JR. The ethics of animal research: an overview of the debate. In: Garrett JR, editor. The ethics of animal research: exploring the controversy. MIT: USA; 2012. p. 1-16.

9. Bass R. Lives in the balance: utilitarianism and animal research. In: Garrett JR, editor. The ethics of animal research: exploring the controversy. MIT: USA; 2012. p. 81-105.

10. Antonic A, Sena ES, Lees JS, Wills TE, Skeers P, Batchelor PE, Macleod MR, Howells DW. Stem cell transplantation in traumatic spinal cord injury: a systematic review and meta-analysis of animal studies. PLoS Biol. 2013:11(12):e1001738

11. Watzlawick R, Sena ES, Dirnagl U. Effect of reporting bias of RhoA/ROCK Blockade intervention on locomotor recovery after spinal cord injury: a systematic review and meta-analysis. JAMA Neurol. 2014;71(1):91-9.

12. Sena ES, van der Worp HB, Bath PM, Howells DW, Macleod MR. Publication bias in reports of animal stroke studies leads to major overstatement of efficacy. PLoS Biol. 2010;8:e1000344

13. Pedder $H$, Vesterinen HM, Macleod MR, Wardlaw JM. Systematic review and meta-analysis of interventions tested in animal models of lacunar stroke. Stroke. 2014:45:563-70.

14. Macleod MR, O'Collins T, Howells DW, Donnan GA. Pooling of animal experimental data reveals influence of study design and publication bias. Stroke. 2004;35:1203-8.
15. Sena ES, Briscoe CL, Howells DW, Donnan GA, Sandercook PA, Macleod MR. Factors affecting the apparent efficacy and safety of tissue plasminogen activator in thrombotic occlusion models of stroke: systematic review and meta-analysis. J Cereb Blood Flow Metab. 2010;30:1905-13.

16. Kwon BK, Okon EB, Tsai E, Beattie MS, Bresnahan JC, Magnuson DK, et al. A grading system to evaluate objectively the strength of pre-clinical data of acute neuroprotective therapies for clinical translation in spinal cord injury. J Neurotrauma. 2011;28(8):1525-43

17. Anglemyer AT, Krauth D, Bero L. Industry sponsorship and publication bias among animal studies evaluating the effects of statins on atherosclerosis and bone outcomes: a meta-analysis. BMC Med Res Methodol. 2015;15:12.

18. Tsilidis KK, Panagiotou OA, Sena ES, Aretouli E, Evangenlou E, Howells DW, et al. Evaluation of excess significance bias in animal studies of neurological diseases. PLoS Biol. 2013;11(7):e1001609.

19. Timmer A, Hilsden RJ, Cole J, Hailey D, Sutherland LR. Publication bias in gastroenterological research - a retrospective cohort study based on abstracts submitted to a scientific meeting. BMC Med Res Methodol. 2002:2:7.

20. Society of Critical Care Medicine's 37th Critical Care Congress Abstracts. Crit Care Med. 2007;35(12 Suppl):A1-A289.

21. Festing MF, Altman DG. Guidelines for the design and statistical analysis of experiments using laboratory animals. ILAR J. 2002:43(4):244-58.

22. Kilkenny C, Browne WJ, Cuthill IC, Emerson M, Altman DG. Improving bioscience research reporting: the ARRIVE guidelines for reporting animal research. PLoS Biol. 2010;8(6):e1000412.

23. Institute for Laboratory Animal Research, National Research Council. Guidance for the description of animal research in scientific publications. Washington DC: National Academy of Sciences; 2011

24. Canadian Council on Animal Care in science. CCAC Guidelines on: choosing an appropriate endpoint in experiments using animals for research, teaching and testing. Ottawa, ON, Canada: Canadian Council on Anima Care; 1998. http://www.ccac.ca/Documents/Standards/Guidelines/ Appropriate endpoint.pdf. Accessed 10 Sep 2016

25. Canadian Council on Animal Care in science: CCAC Guidelines on: animal use protocol review. Ottawa, ON, Canada: Canadian Council on Animal Care; 1997. http://www.ccac.ca/Documents/Standards/Guidelines/Protocol_Review.pdf. Accessed 10 Sep 2016

26. Knobloch K, Yoon U, Rennekampff HO, Vogt PM. Quality of reporting according to the CONSORT, STROBE and Timmer instrument at the American Burn Association (ABA) annual meetings 2000 and 2008. BMC Med Res Methodol. 2011;11:161

27. ter Riet G, Korevaar DA, Leenaars M, Sterk PJ, Van Noorden CFJ, Bouter $L M$, et al. Publication bias in laboratory animal research: a survey on magnitude, drivers, consequences, and potential solutions. PLoS ONE. 2012; 7:e43404

28. Bara M, Joffe AR. The methodological quality of animal research in critical care: the public face of science. Ann Intensiv Care. 2014;4:26.

29. Killkenny C, Parsons N, Kadyszewski E, Festing MFW, Cuthill IC, Fry D, Hutton J, Altman DG. Survey of the quality of experimental design, statistical analysis and reporting of research using animals. PLOS ONE. 2009:4(11):e7284.

30. Sena E, van der Worp B, Howells D, Macleod M. How can we improve the preclinical development of drugs for stroke? Trends Neurosci. 2007;30:433-9

31. Baker D, Lidster $K$, Sottomayor A, Amor S. Two years later: journals are not yet enforcing the ARRIVE guidelines on reporting standards for preclinical animal studies. PLoS Biol. 2014:12(1):e1001756.

32. Landis SC, Amara SG, Asadullah K, Austin CP, Blumenstein R, Bradley EW et al. A call for transparent reporting to optimize the predictive value of preclinical research Nature 2012:490:187-91.

33. Hawkes N. Poor quality animal studies cause clinical trials to follow false leads. BMJ. 2015:351:h5453.

34. Ludbrook J. Interim analyses of data as they accumulate in laboratory experimentation. BMC Med Res Methodol. 2003:3:15.

35. Hooijmans CR, Rovers MM, de Vries RBM, Leenaars M, Ritskes-Hoitinga M, Langendam MW. SYRCLE's risk of bias tool for animal studies. BMC Med Res Methodol. 2014;14:43.

36. Hopewell S, Clarke M, Moher D, Wager E, Middleton P, Altman DG, Schulz KF, CONSORT Group. CONSORT for reporting randomized trials in journal and conference abstracts: explanation and elaboration. PLoS Med. 2008;5(1):e20. 
37. Beller EM, Glasziou PP, Altman DG, Hopewell S, Bastian H, Chalmers I, Gotzsche PC, Lasserson T, Tovey D, for the PRISMA for Abstracts Group. PRISMA for Abstracts: reporting systematic reviews in journal and conference abstracts. PLOS Med. 2013;10(4):e1001419.

38. First draft of the STROBE checklist of items to be included when reporting observational studies in conference abstracts. 2017. https://www.strobestatement.org/fileadmin/Strobe/uploads/checklists/STROBE_checklist_conference_abstract_DRAFT.pdf. Accessed 1 June 2017.
39. Pound P, Bracken MB. Is animal research sufficiently evidence based to be a cornerstone of biomedical research? BMJ. 2014;348:93387.

40. Horrobin DF. Modern biomedical research: an internally self-consistent universe with little contact with medical reality. Nat Rev Drug Discov. 2003:2:151-4.

\section{Submit your next manuscript to BioMed Central and we will help you at every step:}

- We accept pre-submission inquiries

- Our selector tool helps you to find the most relevant journal

- We provide round the clock customer support

- Convenient online submission

- Thorough peer review

- Inclusion in PubMed and all major indexing services

- Maximum visibility for your research

Submit your manuscript at

www.biomedcentral com/submit 